\title{
Well-Defined, Air-Stable (NHC)Pd(allyl)Cl (NHC= N-Heterocyclic Carbene) Catalysts for the Arylation of Ketone
}

\author{
Mihai S. Viciu, Romain F. Germaneau and Steven P. Nolan* \\ Department of Chemistry \\ University of New Orleans \\ New Orleans, Louisiana 70148
}

\section{Supporting Information}

- General Considerations: All aryl halides and ketones were used distilled over $\mathrm{MgSO}_{4}$ (Aldrich). THF (Aldrich) was dried and distilled over Na/benzophenone. $\mathrm{NaO}^{t} \mathrm{Bu}$ (Aldrich) was sublimed in a cold finger apparatus and was stored in a MBraun glovebox. Palladium chloride was purchased from Strem Chemical Company. Allyl chloride (Aldrich) was used as received. Flash chromatography was performed on silica gel 60 (320-400 mesh) with hexanes/ethyl acetate or hexanes/THF.

- The imidazolium salts: IPrHCl, SIPrHCl, ItBuHCl and IMesHCl and corresponding carbenes were synthesized according to literature procedures. ${ }^{1}$

- ${ }^{1} \mathrm{H}$ and ${ }^{13} \mathrm{C}$ NMR spectra were recorded on Varian-300 or Varian-400 MHz spectrometer at room temperature. Deuterated solvents were purchased from Cambridge Isotope Laboratories, Inc. and dried with appropriate drying agents prior to use.

- Elemental analysis was performed by Desert Analysis, Tucson, AZ.

- Reactions were performed in oven dried, screw cap vials with magnetic stirring, under argon atmosphere. The septa were used to prevent solvent evaporation.

- All reported yields are isolated yields and are the average of two runs.

(SIPr)Pd(Cl)allyl (2): SIPr carbene (2 mmol, $780 \mathrm{mg})$ and $[\mathrm{Pd}(\text { allyl }) \mathrm{Cl}]_{2}(1 \mathrm{mmol}, 365.8$ $\mathrm{mg}$ ) were mixed together in a Schlenk tube in the drybox. Dry THF (20 ml) was added by cannula and stirred at room temperature for $30 \mathrm{~min}$. THF was removed in vacuum and 40 
$\mathrm{ml}$ of anhydrous hexane was added to precipitate the product. The product was filtered in air and washed with hexane. Yield 96\% (1.10 g)

${ }^{1} \mathrm{H}-\mathrm{NMR}\left(400 \mathrm{MHz} \mathrm{CDCl}_{3}\right)$ : 7.35(t, 2H), 7.26 (d., 2H), 7.20(overlapped with solvent, $\left.2 \mathrm{H}\right)$, $4.75(\mathrm{~m}, 1 \mathrm{H}), 4.0-4.07(\mathrm{~m}, 4 \mathrm{H}), 3.88(\mathrm{dd}, 1 \mathrm{H}), 3.39-3.54(\mathrm{~m}, 4 \mathrm{H}), 3.01(\mathrm{~d}, 1 \mathrm{H}), 2.73(\mathrm{~d}$, 1H), 1.55 (s, 1H), 1.46(d, 6H), 1.36(d, 6H), 1.28(d, 6H), 1.24(d, 6H).

${ }^{13} \mathrm{C}-\mathrm{NMR}\left(400 \mathrm{MHz} \mathrm{C}_{6} \mathrm{D}_{6}\right): 24.21,24.39,26.95,29.03,29.14,50.02,54.32,72.74$, 109.90, 114.55, 124.87, 129.74, 137.26, 147.89, 148.14, 215.38.

Elemental analysis:

Anal. Calcd.: C, 62.80, H, 7.51, N, 4.89.

Found: C, 62.61; H, 7.51; N, 5.13.

Reaction Procedure for $\alpha$-Arylation of Ketone: In a typical procedure, a reaction vial containing a magnetic stirring bar was loaded inside the drybox with $4 \mathrm{ml}$ dry THF, 100 $\mathrm{mg} \mathrm{NaO}{ }^{t} \mathrm{Bu}$ and $5.6 \mathrm{mg}(\mathrm{SIPr}) \mathrm{Pd}($ allyl $) \mathrm{Cl}$. The ketone $(1.0 \mathrm{mmol})$ and aryl halide $(1.0$ mmol) were added outside of dry box, through the septum fitted cap using a syringe. When one or both substrates were solids they were loaded in the drybox. The reaction was carried out at the indicated temperature. All reactions were conducted under inert atmosphere and monitored by GC. After consumption of reactants, the reactions were quenched with water and extracted in diethyl ether. The organic layer was dried over $\mathrm{Na}_{2} \mathrm{SO}_{4}$, mixed with silica gel and evaporated. The product/silica gel mixture was placed at the top of a flash chromatography column and eluted using an ethyl acetate/hexane (1:10) mixtures.

1-phenyl-2-[4-(trifluoromethyl)phenyl]-1-propanone ${ }^{2}$ (Table 2 Entry 1) The general procedure afforded $225 \mathrm{mg}(81 \%)$ of the title compound.

2-(p-methoxyphenyl)-acetophenone ${ }^{3}$ (Table 2 Entry 2) The general procedure afforded $176 \mathrm{mg}(78 \%)$ of the title compound.

2-(phenyl)-acetophenone ${ }^{3}$ (Table 2 Entry 3) The general procedure afforded $182 \mathrm{mg}$ (93\%) of the title compound.

2-Phenyl-1-tetralone ${ }^{4}$ (Table 2 Entry 4) The general procedure afforded $111 \mathrm{mg}$ $(50 \%)$ of the title compound. 
2,4-diphenyl- 3-pentanone ${ }^{5}$ (Table 2 Entry 5). The general procedure using $2 \mathrm{mmol}$ of base and $2 \mathrm{mmol}$ of aryl halide afforded $209 \mathrm{mg}(88 \%)$ of the desired product.

1-phenyl-2-[3-(methoxy)phenyl]-1-propanone ${ }^{7}$ (Table 2 Entry 6$)$ The general procedure afforded $197 \mathrm{mg}(88 \%)$ of the title compound.

1-phenyl-2-(phenyl)- 1-propanone ${ }^{7}$ (Table 2 Entry 7) The general procedure afforded $191 \mathrm{mg}(91 \%)$ of the title compound.

1-(1-naphthyl)-2-phenylethanone ${ }^{6}$ (Table 2 Entry 8 ) The general procedure afforded $86 \mathrm{mg}(35 \%)$ of the title compound.

1-phenyl-2-(3-pyridinyl)- 1-propanone ${ }^{7}($ Table 2 Entry 9) The general procedure afforded $126.5 \mathrm{mg}(60 \%)$ of the title compound.

2-(4-benzoylphenyl)-1-phenyl-1-propanone ${ }^{7}$ (Table 2 Entry 10) The general procedure afforded $223 \mathrm{mg}(71 \%)$ of the title compound.

1-phenyl-2-(2,4,6-trimethylphenyl)- 1-propanone ${ }^{8}$ (Table 3 Entry 1) The general procedure afforded $181.5 \mathrm{mg}(72 \%)$ of the title compound.

2-(2-methoxyphenyl)-1-phenyl-1-propanone ${ }^{9}$ (Table 3 Entry 2) The general procedure afforded $192 \mathrm{mg}(80 \%)$ of the title compound.

2-(2-methylphenyl)-1-phenyl- 1-propanone ${ }^{10}$ (Table 3 Entry 3) The general procedure afforded $195 \mathrm{mg}(87 \%)$ of the title compound.

2-(2-methylphenyl)-1-phenyl- ethanone ${ }^{7}$ (Table 3 Entry 4) The general procedure afforded $189 \mathrm{mg}(90 \%)$ of the title compound.

$\alpha$-(2-methylphenyl)-tetralone ${ }^{7}$ (Table 3 Entry 5) The general procedure afforded 212 $\mathrm{mg}(90 \%)$ of the title compound. ${ }^{1} \mathrm{H}-\mathrm{NMR}(400 \mathrm{MHz}): 8.1(\mathrm{~d}, 1 \mathrm{H}), 7.5(1 \mathrm{H}), 7.4-7.2$ (m, 6H), $3.92(\mathrm{t}, 1 \mathrm{H}), 3.0-3.1(\mathrm{~m}, 2 \mathrm{H}), 2.42(\mathrm{t}, 2 \mathrm{H}) ; 2.39(\mathrm{~s}, 3 \mathrm{H})$.

2-(2-methoxyphenyl)-1-phenyl- ethanone ${ }^{9}$ (Table 3 Entry 6) The general procedure afforded $181 \mathrm{mg}(80 \%)$ of the title compound.

1-(2-methoxyphenyl)-3,3-dimethyl-2-butanone ${ }^{11}$ (Table 3 Entry 7 ) The general procedure afforded $175 \mathrm{mg}(91 \%)$ of the title compound.

2-(2,4,6-trimethylphenyl)- 3-pentanone ${ }^{12}$ (Table 3 Entry 8) The general procedure afforded $139 \mathrm{mg}(68 \%)$ of the title compound.

1-phenyl-2-(phenyl)- 1-propanone ${ }^{7}$ (Table 4 Entry 1) The general procedure afforded $191 \mathrm{mg}(91 \%)$ of the title compound. 
2-phenyl-3-pentanone ${ }^{13}$ (Table 4 Entry 2) The general procedure afforded $87 \%$ of the title compound by NMR. Yield was determined by NMR in view of the volatility of the product.

2-(4-methylphenyl)-1-phenyl-1-propanone ${ }^{10}$ (Table 4 Entry 3) The general procedure afforded $208 \mathrm{mg}$ (93\%) of the title compound.

2-(4-methylphenyl)-1-phenyl-ethanone ${ }^{14}$ (Table 4 Entry 4) The general procedure afforded $185 \mathrm{mg}(88 \%)$ of the title compound.

2-(4-methoxyphenyl)-1-phenyl-1-propanone ${ }^{7}$ (Table 4 Entry 5) The general procedure afforded $216 \mathrm{mg}(90 \%)$ of the title compound.

2-(p-methoxyphenyl)-acetophenone ${ }^{3}$ (Table 4 Entry 6) The general procedure afforded $196.5 \mathrm{mg}(87 \%)$ of the title compound.

1) (a) Arduengo, A. J. III. US patent 5077 414, 1991; (b) Kelly, R.A.; Sommer, W.; Nolan, S. P. manuscript in preparation.

2) Nicolaou, K. C.; Montagnon, T.; Baran, P. S.; Zhong, Y.-L. J.Am.Chem Soc., 2002, 124 , 2245-2258.

3) Hamann, B.C.; Hartwig, J.F. J. Am. Chem. Soc., 1997, 119, 12382-12383.

4) Wang, D,Z.; Kim, Y.-J.; Streitwieser, A. J. Am. Chem. Soc., 2000, 122, 10754-10760.

5) Dolhem, E.; Ocafrain, M.; Nedelec, J. Y.; Troupel, M Tetrahedron, 1997, 53, 17089-17096.

6) Baumgartner, M.T.; Gallego, M.H.; Pierini, A.B. $\quad$ J. Org. Chem., 1998, 63, 6394-6397.

7) Kawatsura, M.; Hartwig, J.F. J. Am. Chem. Soc., 1999, 121, 1473-1478.

8) Wagner, P.J.; Zhou, B. J. Am. Chem. Soc ,1988, 110, 611-612.

9) Bell, H. C.; Pinhey, J.T.; Sternhell, S. Aust. J. Chem., 1982, 35, 2237-2245.

10) Culkin, D.A.; Hartwig, J.F. J. Am. Chem. Soc., 2001, 123, 5816-5817.

11) Beugelmans, R.; Ginsburg, H. J. Chem. Soc., Chem. Commun., 1980, 11, 508-509.

12) Bunnett, J.F.; Sundberg, J.E. J. Org. Chem., 1976, 41, 1702-1706.

13) Rathke, M.W.; Vogiazoglou, D. J. Org. Chem., 1987, 52, 3697-3698.

14) Angle, S.R.; Neitzel, M.L. J. Org. Chem., 2000, 65, 6458-6461. 